\title{
Recipient-Specific Tolerance after HLA-Mismatched Umbilical Cord Blood Stem Cell Transplantation
}

\author{
Thomas O. Kleen, ${ }^{1}$ Suzanne Kadereit, ${ }^{2}$ Laura R. Fanning, ${ }^{2}$ Jennifer Jaroscak, ${ }^{3}$ \\ Pingfu Fu, ${ }^{4}$ Howard J. Meyerson, ${ }^{1}$ Lara Kulchycki, ${ }^{2}$ Laura F. Slivka, ${ }^{2}$ Margaret Kozik, ${ }^{2}$ \\ Magdalena Tary-Lehmann, ${ }^{1}$ and Mary J. Laughlin ${ }^{1,2,5}$
}

\begin{abstract}
Background. Lower incidence and severity of acute graft versus host disease (GVHD) has been observed in leukemia patients receiving HLA-mismatched umbilical cord (UCB) transplants. However, despite the increased use of UCB in stem cell transplantation, the mechanisms underlying these favorable outcomes are not well delineated.

Methods. We analyzed antigen specific lymphocyte responses after transplant to determine whether the decreased allogeneic responsiveness of UCB lymphocytes is attributable to pan-unresponsiveness, lymphocyte repressive or recipient-specific tolerance.

Results. Circulating lymphocytes collected early (3 months) after UCB transplant demonstrate a less naïve phenotype compared with that in the infused graft. Additionally, after transplant, circulating peripheral blood UCB-derived lymphocytes produced normal levels of interferon- $\gamma$ and proliferated normally when stimulated with mitogen or third party alloantigen. In contrast, when stimulated with recipient antigen, circulating lymphocytes emerging posttransplant did not proliferate nor produce interferon- $\gamma$. Moreover, analysis of interleukin-4 production revealed a Th2 response to recipient antigens. These data indicate early induction of immune tolerance of naïve UCB graft lymphocytes with skewing of transplant recipient-specific immune response towards Th2 cytokine profile.

Conclusions. UCB graft lymphocyte immune naivety and observed early tolerance induction may contribute to the observed favorable GVHD incidence, despite infusion of HLA mismatch grafts in the unrelated allogeneic setting.
\end{abstract}

Keywords: Immune tolerance, Hematopoietic stem cell transplant, Umbilical cord blood.

A llogeneic bone marrow transplantation (BMT) is an effective medical therapy for life-threatening hematologic disorders (1). However, use of BMT is limited by lack of available human leukocyte antigen (HLA)-matched donors. Umbilical cord blood (UCB) has emerged from this background as an alternative stem cell source due to its ready availability and its effectiveness despite HLA-disparity of one or more antigens (2-5).

Graft versus host disease (GVHD), a major impediment to successful allogeneic stem cell transplantation, is mediated by donor T-cell alloreactivity directed against major and minor histocompatibility antigens presented by recipient antigen presenting cells. In addition, recent studies have identified a potential role of early recovering natural killer (NK)

This work was supported by: RO1-AI47756 (MTL), RO1-AI47289-01 (MJL), Abraham J. \& Phyllis Katz Foundation, and Elsa U. Pardee Foundation. M.J. Laughlin is a Leukemia Scholar in Clinical Research, Leukemia and Lymphoma Society of America.

${ }^{1}$ Department of Pathology, School of Medicine, Case Western Reserve University, Cleveland, $\mathrm{OH}$.

${ }^{2}$ Department of Medicine, School of Medicine, Case Western Reserve University, Case Comprehensive Cancer Center, Cleveland, $\mathrm{OH}$.

${ }^{3}$ Department of Pediatrics, School of Medicine, Case Western Reserve University, Case Comprehensive Cancer Center, Cleveland, $\mathrm{OH}$.

${ }^{4}$ Department of Epidemiology and Biostatistics, School of Medicine, Case Western Reserve University, Case Comprehensive Cancer Center, Cleveland, $\mathrm{OH}$

${ }^{5}$ Address correspondence to: Mary J. Laughlin, M.D., Case Western Reserve University, 10900 Euclid Ave., WRB2-129, Cleveland, OH 44106-7284.

E-mail: Mary.Laughlin@case.edu.

Dr. Tary-Lehmann and Dr. Laughlin share senior authorship of this paper. cells expressing killer immunoglobulin-like receptors (KIR) in mitigating GVHD immune reactivity at early time points after allogeneic transplant (6). A third important lymphocyte population participating in allogeneic reactivity include Tregulatory cells, which have been shown to inhibit immune responses in vivo after allogeneic BMT in murine models (7). Whether or not a patient develops GVHD is determined by the interactions of these donor immune cells with recipient antigen presenting cells.

Clinical reports identify that despite infusion of HLAdisparate lymphocytes, UCB grafts elicit low rates of acute GVHD, possibly due to the immune naivety of the infused neonatal T cells $(2,3,8-12)$. UCB contains approximately $30-50 \% \mathrm{CD}^{+}{ }^{+}$-cells with predominant $\mathrm{CD} 45 \mathrm{RA}^{+}$naïve phenotype. It has been shown that activated UCB T-cells produce lower amounts of Th1 and Th2 cytokines after in vitro stimulation as compared to adult T-cells, including interferon- $\gamma($ IFN- $\gamma$ ) and tumor necrosis factor- $\alpha$ (TNF- $\alpha$ ), cytokines known to play an important role in amplifying T-cell allogeneic responses, and contributing to clinical manifestations of GVHD $(13,14)$. Moreover, although UCB T-cells proliferate at rates equivalent to adult $\mathrm{T}$-cells in response to primary stimulation, alloantigen-specific cytotoxicity is reduced in UCB T-cells after secondary stimulation $(15,16)$.

This report outlines studies focused on immune reactivity measured in adults with hematologic malignancies treated with myeloablative conditioning and infused with banked unrelated allogeneic HLA-disparate neonatal UCB stem cell grafts. We report herein, lymphocyte analyses performed on UCB grafts and their progeny emerging in adult hematology patients within the first 3 months after infusion. We hypothesize that infused UCB graft lymphocytes may have the capability of developing tolerance to recipient anti- 
gens, accounting in part for clinical observations of reduced GVHD in cord blood transplant recipients. We therefore analyzed lymphocyte surface phenotypes and functionality including responsiveness to recipient antigens 3 months after UCB transplant. Immunophenotyping studies revealed a maturation of the UCB donor-derived T cells from naive (CD45RA) to memory (CD45RO). Lymphocyte proliferation and cytokine production studies revealed that although a robust response to third party antigens and/or mitogen stimulation by the UCB donor lymphocytes was maintained, there was reduced immune response overall to patient antigens. Our results suggest recipient immune tolerance induction over pan-unresponsiveness lymphocyte suppression or lymphocyte suppression exhibited by donor-derived lymphocytes emerging at early time points after HLA mismatched unrelated UCB allogeneic stem cell transplant.

\section{PATIENTS AND IMETHODS}

\section{Patients, UCB Grafts, and Sample Collection}

The Institutional Review Board of Case Western Reserve University/University Hospitals of Cleveland approved the clinical protocol for UCB transplantation; written informed consent was obtained from all patients. Study patients included adults with hematologic malignancies consecutively treated with full myeloablative conditioning regimens; followed by transplants of single unit HLA-mismatched umbilical cord blood, which was thawed and directly infused without in vitro expansion. Graft selection, HLA typing, cord blood processing, preparative regimens, transplantation procedure, supportive care and prophylaxis against GVHD were performed as previously described (9). Chimerism was evaluated in all study patients by fluorescent in situ hybridization (FISH) for the Y chromosome in sex-mismatched transplants, or DRB1 allele-specific hybridization in cases in which the donor and patient differed at HLA-DR, or use of quantitative PCR for microsatellite DNA markers.

\section{Cells}

Peripheral blood was collected from transplant patients and healthy adult donors, and peripheral blood mononuclear cells (PBMC) were isolated by Ficoll-Histopaque $(1.077 \mathrm{~g} / \mathrm{ml})$ (Sigma Chemical, St. Louis, MO) density gradient centrifugation, and cryopreserved with $10 \% \mathrm{v} / \mathrm{v}$ dimethylsulfoxide until further study. Peripheral blood from UCB transplant recipients was collected prior to administration of myeloablative regimen and transplantation as well as 3 months after transplant. To ensure consistency within stimulator lymphocyte populations, irradiated (100 Gy) cloned homozygous HLA-DRB ${ }^{\star} 0101$-positive EBV-transformed positive B cell clone, LG2 was used (National Institute of Cancer Research, Genoa, Italy) (17-19). LG2 cells were HLA typed and compared with UCB graft and study patient HLA genotypes; LG2 cells were HLA disparate with all study patients and UCB grafts. Of 20 patients consecutively transplanted at this institution, experiments and data presented were performed on nine patients surviving at the time of study.

\section{MLC ELISPOT Assays and Proliferation Assay}

The assays were performed as described previously (20). Briefly, ImmunoSpot plates P50 or M200 (Cellular
Technology Ltd, Cleveland, $\mathrm{OH}$ ) were coated overnight at $4^{\circ} \mathrm{C}$ with capture antibodies $(\mathrm{Ab})$ that were specific for either IFN- $\gamma 2 \mathrm{G} 1$ (Endogen, Woburn, MA) at $2 \mu \mathrm{g} / \mathrm{ml}$ or anti-interleukin-4 (IL-4) Ab 8D4-8 (BD PharMingen, San Diego, $\mathrm{CA})$ at $4 \mu \mathrm{g} / \mathrm{ml}$. The plates were blocked with BSA ( $10 \mathrm{~g} / \mathrm{L}$ in PBS).

Mixed lymphocyte cultures (MLC) were performed using patient's PBMC, obtained 3 months after transplant or healthy adults as responders. Stimulator cells included either: a) recipient PBMC collected from the respective patient prior to myeloablative regimen and transplantation (host), or b.) LG2 cells (3rd-party). Stimulator cells were irradiated (30Gy) and incubated with responder cells in complete RPMI media (94\% RPMI $+5 \% \mathrm{ABO}$ serum $+1 \%$ L-glutamine). The responder/stimulator ratio was $1: 1$, plating 0.1 or $0.3 \times 10^{6}$ cells/well as indicated, in triplicate. Responder PBMC activated with phytohemagglutinin (PHA) (Sigma Chemical) at $10 \mu \mathrm{g} / \mathrm{ml}$ final concentration served as positive controls. Negative control wells contained responder PBMC in media alone. After $24 \mathrm{~h}$ for IFN- $\gamma$ assays, or after $48 \mathrm{~h}$ for IL- 4 assays, the plates were washed and biotinylated detection antibodies were added for $12 \mathrm{~h}$, at $4^{\circ} \mathrm{C}$. The following monoclonal $\mathrm{Abs}$ were used: IFN- $\gamma$ (B133.5 Endogen) at $2 \mu \mathrm{g} / \mathrm{ml}$ and IL-4 (MP4-25D2 PharMingen) at $3 \mu \mathrm{g} / \mathrm{ml}$. The plates were developed for 10-20 $\mathrm{min}$ for IFN- $\gamma$ assays, and 45-60 $\mathrm{min}$ for IL-4 assays. The plates were air dried overnight and subjected to image analysis using an ImmunoSpot Image Analyzer (Cellular Technology, Cleveland, OH). For the proliferation assays the setup was identical as above only that the cells were plated in 96 well round-bottom tissue culture plates (Costar, Corning, NY) and after a 4 day culture $1 \mu \mathrm{Ci}\left[{ }^{3} \mathrm{H}\right]$ thymidine was added to each well. The plates were harvested after $18 \mathrm{~h}$, and $\left[{ }^{3} \mathrm{H}\right]$ thymidine incorporation was assayed by liquid scintillation counting. The results are expressed as incorporation of radiolabel (mean \pm SEM).

\section{Flow Cytometric Analysis and Cell Separation}

UCB graft mononuclear cells and PBMC from patients at 3 months after transplant were stained for $30 \mathrm{~min}$ on ice with the following antibodies and appropriate isotype controls: CD3, CD4, CD8, CD34, CD45RO, CD45RA, and CD45 (Becton Dickinson, San Jose, CA and Beckman-Coulter, Fullerton, CA); added in four-color combinations (FITC, PE, PerCP and APC). Minimum 20,000 events were acquired on an Elite ESP flow cytometer (Coulter, Miami, FL) and analyzed with WinList (Verity Software House Inc, Topsham, $\mathrm{MN})$. In T-cell selection studies, $\mathrm{CD}^{+}$cells were isolated from PBMC by negative selection using RosetteSep enrichment cocktails (Stemcell Technologies, Vancouver). The Tcell depletion cocktail (RosetteSep) was also used to select antigen presenting cells (APC). The specified cell fractions isolated were of $>96 \%$ purity confirmed by flow cytometry (data not shown).

\section{RESULTS}

\section{Patients and Outcomes}

This study included nine evaluable adult patients with hematologic malignancies of an initial cohort of 20 patients enrolled in a single institution phase I clinical trial who were consecutively transplanted with HLA-mismatched unrelated 
UCB after receiving full ablative conditioning, and who engrafted and survived $>90$ days. Patient and graft characteristics and transplant outcomes are shown in Tables 1-3. All patients underwent UCB transplantation for treatment of high risk or recurrent leukemia (Table 1). UCB donor-derived neutrophil engraftment $\left(\mathrm{ANC}>500 \times 10^{9} / \mathrm{L}\right)$ occurred on average 25 days after transplant (range: 13-36) (Table 2). Severe acute GVHD (grades III-IV) was observed in only 3 patients despite infusion of UCB grafts mismatched at $\geq 1$ HLA loci. Five patients are alive and event free at median follow up 38 months (range 10-74 months).

\section{Graft Analysis}

UCB graft analyses included HLA analyses, and surface immunophenotyping prior to infusion, according to methods previously described (9). The infused UCB grafts were HLA mismatched in all patients, including: 3/6 matched loci in 2 patients, $4 / 6$ in 6 patients, and one patient received a 5/6 HLA matched graft (Table 2). The median dose of CD34 ${ }^{+}$ and total nucleated cells infused were: $0.839 \mathrm{CD} 34^{+} / \mathrm{kg}$ recipient weight (range $0.366-1.16$ ) and $1.75 \times 10^{7}$ cell/kg (range $1.22-4.51$ ) respectively (Table 2 ). HLA disparities were restricted to class I loci in 4 patients while 5 patients received grafts disparate at class I and class II (DRB1) loci. Notably, though UCB CD $34^{+}$median cell dose was one log lower than conventional bone marrow grafts, median $\mathrm{CD} 3{ }^{+}$infused cell dose: $5.4 \times 10^{6}$ (range 4.47-27.4), was comparable to standard marrow graft infusions (Table 2) (21).

PBMC were collected from all patients at 3 months after UCB stem cell transplant and surface immunophenotyping was performed. Full donor chimerism (>98\% donor) was noted in PBMC in all transplant patients (Table 3). CD4, CD8, CD45RA and CD45RO expression on the circulating UCB donor-derived T-cells measured at 3 months after transplant were compared with that initially infused in the UCB stem cell graft (Fig. 1A-D). UCB graft infused CD3+ T-cells expressed predominantly CD4 phenotype (Fig. 1A), while in two patients this shifted towards CD8 expression at 3 months posttransplant (Fig. 1B). Interestingly, while infused UCB graft lymphocytes expressed predominantly naive CD45RA phenotype with very few CD45RO cells (Fig. 1C), percentages

\section{TABLE 1. Patient characteristics}

\begin{tabular}{lc}
\multicolumn{1}{c}{ Demographics } & Value \\
\hline Age (years) & 30 \\
Median & $24-50$ \\
Range & \\
Weight (kg) & 71 \\
Median & $58-112$ \\
Range & \\
Disease (no. patients) & 2 \\
Acute lymphoblastic leukemia & 2 \\
1st or 2nd complete remission & 3 \\
Acute myeloid leukemia & 2 \\
1st or 2nd complete remission & 1 \\
Advanced disease & 4 \\
Chronic myeloid leukemia & 0 \\
First chronic phase & 4 \\
Advanced disease & \\
\hline
\end{tabular}

of CD45RO ${ }^{+}$lymphocytes were significantly $(P=0.0024)$ increased in circulating UCB donor-derived T-cells at early time points (3 months) after UCB stem cell graft infusion (Fig. 1D). Absolute lymphocyte counts normalized in the majority $(n=6)$ of the 9 study patients at time points 3 months posttransplant, when immunophenotyping and functional MLC were performed, with median counts $1.20 \times 10^{9} / \mathrm{L}$ (range: $0.126-4.32 \times 10^{9} / \mathrm{L}$ ) in the entire cohort.

\section{Immune Response Assays}

The functional characteristics of early post engraftment circulating lymphocytes were tested by measuring their capability to produce IFN- $\gamma$ in mixed lymphocyte culture. We performed ELISPOT assays (20) to measure mitogen (PHA) and allogeneic stimulation-induced IFN- $\gamma$ production by PBMC collected from UCB transplant patients 3 months after transplant.

To verify T-cell specificity of IFN- $\gamma$ production observed upon mitogenic and allogeneic stimulation and to exclude possible production by monocytes, B and/or NK cells present in PBMC, T cell separation experiments were performed. ELISPOT assays were conducted to compare responses of whole PBMC with that of purified T-cells in combination with irradiated autologous antigen-presenting cells (APC) and APC alone from one representative UCB study patient (whom had sufficient available cells) at day 90 after transplantation (Fig. 2A). After 24h of PHA stimulation, PBMC (striped bars) and selected T-cells stimulated with autologous irradiated APC (full bars) contained equivalent numbers of IFN- $\gamma$ producing cells, while APC alone (empty bars) produced no significant IFN- $\gamma$, thus confirming T-cellspecificity of the observed IFN- $\gamma$ production (Fig. $2 \mathrm{~A}$ ). The same T-cell-specificity of IFN- $\gamma$ production was observed after $24 \mathrm{~h}$ of allogeneic stimulation with LG2 cells. Within allogeneic stimulated APC, no IFN- $\gamma$ producing cells were observed (Fig. 2A). Equivalent results of unselected PBMC, T-cell and APC IFN- $\gamma$ producing cells were measured in healthy controls (data not shown). Both patient and healthy control results confirm T-cell specificity of the IFN- $\gamma$ production during allogeneic stimulation of whole PBMC.

Subsequent experiments were performed with mixed lymphocyte cultures with UCB donor-derived study patients' PBMC as responder cells (without T-cell separation) to minimize cell loss for complete analyses. UCB donor-derived PBMC from study patients were assessed for their capability to produce IFN- $\gamma$ after PHA stimulation by ELISPOT (Fig. 2B). All patients displayed significant numbers (median 1,079 spots $/ 10^{6}$ PBMC plated, range $100-1,870$ spots $/ 10^{6} \mathrm{PBMC}$ ) of IFN- $\gamma$ producing cells, comparable to responses observed in healthy adults (22). This assay demonstrates that all of the patient cells tested had the capacity to produce IFN- $\gamma$ upon stimulation, indicating that lack of IFN- $\gamma$ production is not an artifact of the study method but a specific response.

Further experiments were performed to characterize the reactivity of newly circulating donor lymphocytes towards the transplant recipient antigens, and compared with responses to third party HLA disparate antigens. Th1/Th2 cytokine profiles and proliferative response of early circulating lymphocytes in UCB transplant patients were measured in MLC. Responder cells included PBMC collected from UCB transplant patients $(n=3)$ at 3 months after graft infusion, 
TABLE 2. Graft characteristics

\begin{tabular}{|c|c|c|c|c|c|}
\hline Study & HLA match & Loci of HLA disparity (graft/patient) & $\begin{array}{c}\text { Cell dose } \\
\left(\times 10^{7} / \mathrm{kg}\right) \\
\text { infused }\end{array}$ & $\begin{array}{c}\text { CD34 } \\
\left(\times 10^{5} / \mathrm{kg}\right) \\
\text { infused }\end{array}$ & $\begin{array}{c}\text { CD3 } \\
\left(\times 10^{6} / \mathrm{kg}\right) \\
\text { infused }\end{array}$ \\
\hline 1 & $5 / 6$ & A: $31 / 11$ & 2.07 & 0.871 & 5.03 \\
\hline 2 & $4 / 6$ & A: $1 / 3,2 / 23$ & 2.57 & 0.565 & 8.92 \\
\hline 3 & $3 / 6$ & A: 2/24; B: 7/13; DRB1 1301/blank & 3.96 & $\mathrm{~N} / \mathrm{E}$ & 6.08 \\
\hline 4 & $4 / 6$ & A: $28 / 2 ; B: 71 / 41$ & 1.22 & 0.366 & 5.72 \\
\hline 5 & $4 / 6$ & B: 55/35; DRB1: 1303/0102 & 1.75 & 0.753 & 4.47 \\
\hline 6 & $3 / 6$ & A: $24 / 29 ; \mathrm{B}: 60 / 62 ; \mathrm{DRB} 1: 1103 / 1301$ & 1.41 & $\mathrm{NE}$ & 5.28 \\
\hline 7 & $4 / 6$ & B: 55/7; DRB1: blank/1501 & 4.51 & 0.884 & 27.4 \\
\hline 8 & $4 / 6$ & B: 14/52; DRB1: 0701/1501 & 1.41 & 0.839 & 5.40 \\
\hline 9 & $4 / 6$ & A: $32 / 03 ; \mathrm{B}: 61 / 35$ & 1.55 & 1.16 & 5.10 \\
\hline
\end{tabular}

NE, not evaluated.

TABLE 3. Patient outcomes

\begin{tabular}{|c|c|c|c|c|c|c|c|c|}
\hline Study & $\begin{array}{c}\text { Day to } \\
\text { engraftment }^{a}\end{array}$ & $\begin{array}{c}\text { Acute } \\
\text { GVHD } \\
\text { grade }\end{array}$ & $\begin{array}{l}\text { Site of } \\
\text { GVHD }\end{array}$ & $\begin{array}{c}\text { Day of } \\
\text { onset of } \\
\text { acute } \\
\text { GVHD }\end{array}$ & GVHD therapy & $\begin{array}{c}\text { Event-free } \\
\text { survival } \\
\text { (days) }\end{array}$ & $\begin{array}{c}\text { Overall } \\
\text { survival } \\
\text { (days) }\end{array}$ & Events \\
\hline 1 & 30 & 2 & Skin & 31 & None & 360 & 521 & Relapse, CNS systemic \\
\hline 2 & 36 & 2 & Skin & 33 & Steroids/CSA & 1101 & 1101 & MOF, sepsis \\
\hline 3 & 21 & 2 & Skin & 15 & None & 2166 & 2166 & Alive, event free \\
\hline 4 & 28 & 3 & Skin/GI & 64 & Steroids/ $\alpha$-CD2 MoAB & 2006 & 2006 & Alive, event free \\
\hline 5 & 20 & 3 & Skin/liver & 15 & Steroids/ $\alpha$-CD 2 MoAB & 265 & 265 & Interstitial pneumonitis \\
\hline 6 & 13 & 3 & Skin/GI & 29 & Steroids/CSA & 919 & 919 & Pulmonary failure \\
\hline 7 & 21 & 1 & Skin & 28 & Steroids/CSA & 1442 & 1442 & Alive, event free \\
\hline 8 & 29 & 0 & None & NA & NA & 827 & 1323 & Alive, controlled relapse \\
\hline 9 & 25 & 0 & None & NA & NA & 1868 & 1868 & Alive, event free \\
\hline
\end{tabular}

${ }^{a}$ Engraftment was first of three consecutive days to attain donor-derived absolute neutrophil count greater or equal to 500 cells $/ \mu \mathrm{L}$.

GVHD, graft versus host disease; CSA, cyclosporine; $\alpha-\mathrm{CD} 2 \mathrm{MoAB}$, anti-CD2 monoclonal antibody; CNS, central nervous system; MOF, multiple organ failure; NA, not available.

stimulated with either: 1) irradiated host PBMC (collected from the respective patients pretransplant), or 2) third-party allogeneic irradiated LG2 B cell stimulator cells. ELISPOT assays were performed for IFN- $\gamma$ producing cells after $24 \mathrm{~h}$, or for IL-4 producing cells after $48 \mathrm{~h}$. Antigen-specific proliferation after 5 days of stimulation was also measured by thymidine incorporation. Analyses showed low IL-4 responses against allogeneic third-party antigens in UCB transplant patients (Fig. 3A) similar to that measured in adult healthy controls (22). Conversely, against allogeneic host antigens, IL-4 production was strongly elevated in the UCB transplant patients, indicating a Th2 shift (Fig. 3A). Strikingly however, none of the UCB patients produced significant amounts of IFN- $\gamma$ upon stimulation with stimulator cells expressing host antigens, whereas IFN- $\gamma$ production against third-party HLA disparate stimulator cells was strong to elevated in all patients tested (Fig. 3A). These results were confirmed with similar patterns of UCB patient PBMC responsiveness observed in proliferation assays run in parallel, demonstrating absent to very low proliferation against cells expressing host antigens and moderate to strong proliferation against third-party antigens (Fig. 3A). These results suggest immune tolerance specific for host antigens with observed Th2 skewing comparing MLC with transplant recipient vs. third party HLA irrelevant stimulator cells. The striking lack of IFN- $\gamma$ production upon stimulation with cells expressing host antigens, when compared to third-party stimulation, was confirmed as shown in Figure 3B $(P=0.045)$.

\section{DISCUSSION}

HLA disparity, including major and minor antigens, between the donor and recipient in allogeneic stem cell transplantation is an important determinant of GVHD. A higher incidence of acute GVHD has been observed in patients transplanted with HLA-matched unrelated grafts when compared with matched sibling grafts, despite HLA matching at high resolution molecular tissue typing. This may be attributable to reactivity of donor $\mathrm{T}$ cells with recipient minor histocompatibility antigens presented within the MHC complex (23). Minor histocompatibility antigen disparity is expectedly greater between unrelated individuals. Early induction of transplantation tolerance is optimal for successful stem cell transplant outcomes, e.g. suppression or elimination of donor lymphocytes in the transplant patient's immune repertoire that are strongly reactive to self antigens; thereby leaving the majority of donor lymphocytes immunocompetent to perform the normal function of host protection after transplantation (24).

Immune naivety of UCB allows successful transplanta- 
A

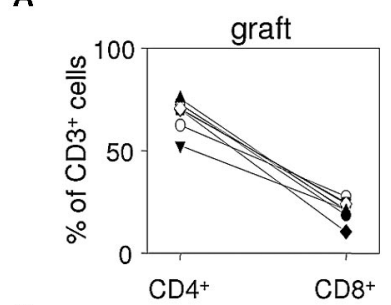

C

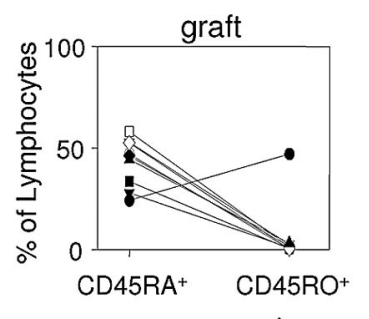

B

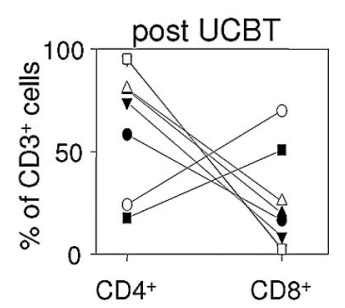

D

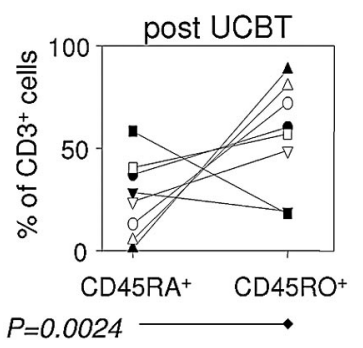

FIGURE 1. Surface phenotype of UCB stem cell graft T lymphocytes and UCB donor-derived circulating peripheral blood T lymphocytes. UCB graft mononuclear cells (MNC) analyzed after thaw prior to infusion and PBMC drawn from patients at three months after transplant were analyzed by flow cytometry for expression of CD3, CD4, CD8, CD45RA and CD45RO. (A) Percent surface expression of CD4 and CD8 on gated CD3 ${ }^{+}$UCB graft MNC at time of infusion. (B) Percent surface expression of CD4 and CD8 on gated $\mathrm{CD}^{+}$circulating patient PBMC three months postUCB transplant. (C) UCB graft surface expression of CD45RA and CD45RO on gated lymphocytes at time of infusion (D) Percent surface expression of CD45RA and CD45RO on gated lymphocytes of circulating patient PBMC three months postUCB transplant. Lines connect the data points of the same patient. CD45RO ${ }^{+}$measured at three months postUCBT was statistically greater than that measured at the time of infusion by paired $t$ test $(P=0.0024)$.

tion from unrelated donors despite HLA disparities at major loci without requirement of graft $\mathrm{T}$ cell depletion, and reconstitutes normal lymphohematopoietic function in the recipient over time (25). Neonatal UCB graft T lymphocytes express a naive phenotype $\left(\mathrm{CD} 45 \mathrm{RA}^{+}\right)$, low level of activation markers, altered cytokine regulation, as well as susceptibility to tolerance induction in vitro $(13,14)$. These phenotypic and functional characteristics of neonatal UCB graft accessory cells may account for the enhanced benefits for UCB recipients, including lower rates and severity of GVHD in the unrelated setting.

The clinical use of UCB grafts in transplantation for patients with hematologic malignancies and lacking a histocompatible donor, takes advantage of the unique characteristics of neonatal adaptive immunity. Clinical reports to date indicate lower incidence and severity of GVHD elicited by UCB grafts $(2,3,5,8)$. Also, relevant murine studies show that neonatal mice are not immune deficient but biased towards Th2 immune responses (26). Importantly, mice initially immunized as neonates mount Th2-dominant memory responses when re-exposed to the same antigens as adults; this offers one potential mechanism underlying the maintained tolerance observed in UCB stem cell transplant recipients in light of a maturing immune system. Human and mouse ne-

A
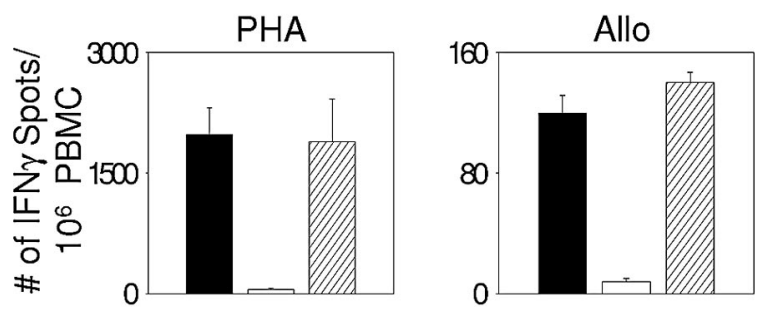

B

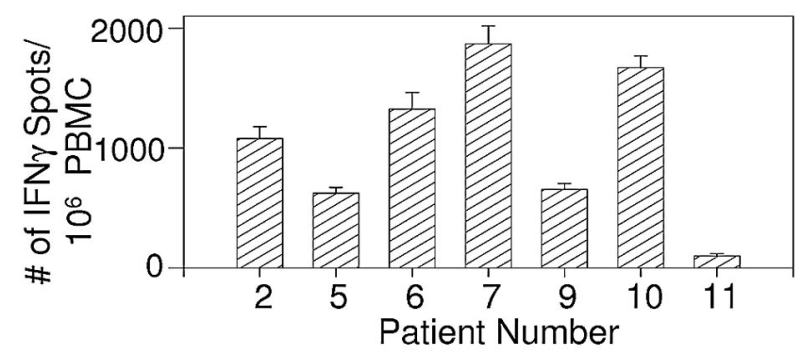

FIGURE 2. IFN- $\gamma$ production by circulating lymphocytes in UCB transplant recipients. 24-h cultures of patient PBMC stimulated by either mitogen (PHA) or allo-antigen (LG2 cells) were assayed for IFN- $\gamma$ producing cells by ELISPOT. To confirm that measured IFN $\gamma$ was not produced by monocytes and/or natural killer cells, CD3 ${ }^{+}$T-cells and APC were selected from PBMC using RosetteSep enrichment cocktails. (A) IFN- $\gamma$ production by selected T-cells combined with irradiated autologous APC (1:1) (solid bars), selected APC (empty bars) and unselected whole PBMC (striped bars), after $24 \mathrm{~h}$ of stimulation with PHA or HLA disparate alloantigen (LG2 cells). Values are mean \pm SEM, $\mathrm{n}=3$. (B) IFN $\gamma$ production by PHA stimulated PBMC from study patients 3 months after UCB transplant. Data expressed as mean \pm standard deviation.

onates under certain circumstances can develop Th1 lineage responses, e.g. responses to Mycobacterium bovis bacillus Calmette-Guerin $(27,28)$, but commonly Th1 responses are limited in magnitude or partially biased to Th2-cell function (29-31). In addition, the quality of the immune response may be affected by the "high antigen load" that the host presents to the neonate engrafting immune system. It has been shown in neonatal mice that an adult-level dose of mouse leukemia virus leads to a Th2 response with no protection from disease, whereas a low level dose leads to Th1 deviation and protection from disease (32).

It is unclear whether the reduced GVHD observed after UCB transplantation compared with bone marrow grafts obtained from adult donors is due to reduced graft lymphocyte number, altered recognition of recipient antigens by $\mathrm{UCB}$ donor T cells interacting with APC, and/or reduction in the amplification response of these naïve donor T cells, activated by recipient alloantigen presented within the context of MHC. These factors may serve to limit the cytokine and cellular cascade necessary to amplify UCB donor lymphocyte alloreactivity to recipient antigens, thereby limiting GVHD (33). Alternatively, the low incidence of GVHD observed in recipients of HLA mismatched UCB may be related to the extensive immunosuppression from the myeloablative preparative regimens provided to ensure donor engraftment, and/or the lower dose of UCB graft lymphocytes infused. 
A

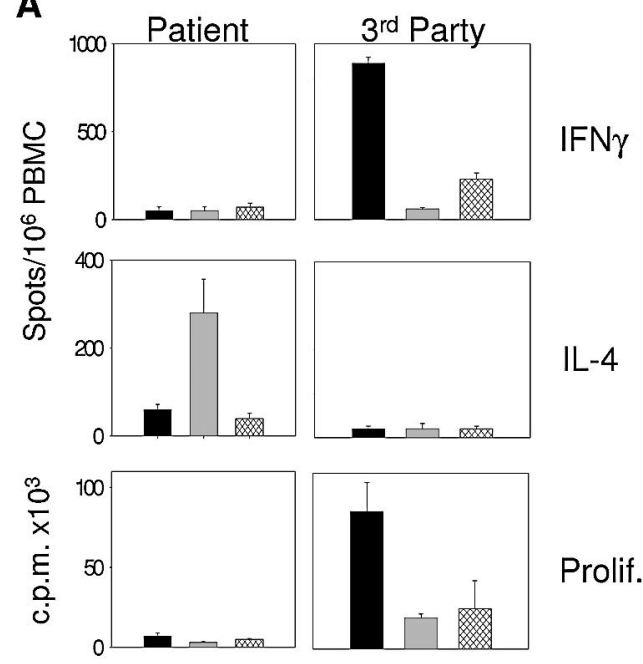

B

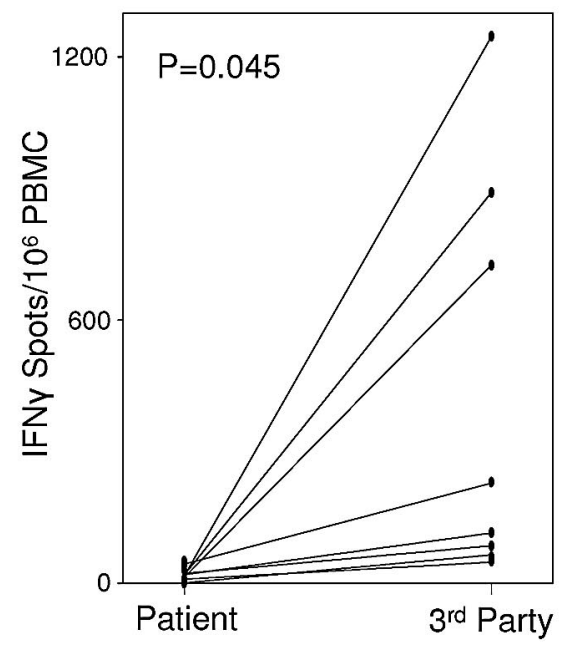

FIGURE 3. Reduced IFN- $\gamma$ production in mixed lymphocyte cultures (MLC) by early circulating UCB transplant patient PBMC in specific response to host antigens. PBMC from adult patients $(n=3) 3$ months postUCBT were assayed in MLC with either patient (pretransplant) or third party HLA disparate stimulator cells, for the number of cytokine producing cells using ELISPOT. Stimulator cells included either irradiated autologous PBMC collected from the respective patients prior to transplant (patient), or HLA-disparate allogeneic LG2 B cells (3rd-party). (A) IFN- $\gamma$ (after 24h) and IL-4 (after 48h) producing cells, as well as proliferation (bottom panels, after 5 days), with patient or HLA disparate third party (LG2) stimulation in MLC. Representative study patients: 1 (solid bar), 2 (gray bar) and 5 (hashed bars) are shown. Values are expressed as mean \pm SEM (B) IFN- $\gamma$ producing cells in PBMC collected 3 months after transplant from UCB study patients after stimulation for $24 \mathrm{~h}$ with the indicated stimulator cells (Host or HLA-mismatched LG2 third party). IFN $\gamma$ production from cells stimulated by third-party antigen was statistically greater than that from patient $(P=0.045$, paired $t$ test). Data points from each patient are connected by a line.

To determine whether the decreased alloresponsiveness of UCB lymphocytes could be attributable to pan-immunosuppression versus recipient-specific donor lymphocyte immune tolerance, we performed mixed lymphocyte cultures (MLC) during the early posttransplant period. Our studies identify that recipient-specific immune tolerance of UCB donor lymphocytes is generated in adult leukemia patients at early time points (3 months) after transplant. Notably, emerging UCB donor lymphocytes did not proliferate in response to recipient PBMC, yet maintained high proliferative responses to third party HLA-disparate allogeneic stimulator cells, indicating recipient-specific tolerance rather than panimmunosuppressed lymphocyte function. These observations were confirmed upon ELISPOT analyses of cytokine production by emerging donor UCB lymphocytes which was skewed toward Th2 (IL-4) production with minimal Th1 cytokines (IFN- $\gamma$ ) produced in the presence of recipient stimulator cells in the majority of patients analyzed. However, donor-derived circulating lymphocytes in UCB transplant recipients maintained the potential for normal Th1-predominant cytokine production including IFN- $\gamma$ in the presence of third party HLA-disparate allogeneic stimulator cells.

Without cell labeling we cannot specify whether circulating donor-derived lymphocytes were expanded from the infused graft, generated de novo from infused UCB stem cells, or whether components of both sources comprise circulating lymphocytes in UCB transplant patients at these early time points. Data previously reported supports the hypothesis that early lymphocyte recovery in UCB adult recipients is primarily due to expansion of infused graft lymphocytes and periph- eral education rather than thymic-derived, with reduced TRECs and oligoclonal $V$ beta repertoire expression observed in these patients (34).

Studies in bone marrow transplant patients have indicated that GVHD may stem from clonal expansion of alloreactive T-cells (35) and humoral response generated by donor immune cell recognition of host MHC (36). Because UCB graft $\mathrm{T}$ lymphocytes primarily express a naive $\mathrm{CD} 4+\mathrm{CD} 45 \mathrm{RA}+$ phenotype, the mechanisms leading to immune tolerance may differ from observations in patients receiving conventional HLA matched stem cell transplants from adult donors containing graft $\mathrm{T}$ lymphocytes expressing memory phenotype $(37,38)$. Clinical studies have demonstrated a lower incidence and severity of GVHD in patients receiving a UCB transplant, despite HLA mismatching of one or more loci $(2,8,9,12)$, supporting the hypothesis that immune tolerance toward recipient antigens may be facilitated by unique features of UCB grafts obtained from neonates.

In summary, early circulating donor-derived peripheral blood lymphocytes in adult leukemia transplant patients infused with HLA-mismatched unrelated UCB stem cell grafts after treatment with full myeloablative conditioning appear immune tolerant to the recipient. UCB graft lymphocyte naivety may allow development of recipient-specific tolerance after unrelated allogeneic stem cell transplantation despite infusion of grafts mismatched at more than one major HLA loci. Further studies to understand the mechanisms of neonatal antigen presentation and lymphocyte maturation and development in UCB stem cell transplant recipients are warranted. 


\section{ACKNOWLEDGIMENTS}

The authors thank the laboratory and clinical staff of the Case Western Reserve University / University Hospitals of Cleveland Ireland Cancer Center Blood and Marrow Transplant Program for their compassion and hard work in the care of their patients.

\section{REFERENCES}

1. Storb R. Allogeneic hematopoietic stem cell transplantation-yesterday, today, and tomorrow. Exp Hematol 2003; 31 (1): 1.

2. Rubinstein P, Carrier C, Scaradavou A, et al. Outcomes among 562 recipients of placental-blood transplants from unrelated donors. New Engl J Med 1998; 339 (22): 1565.

3. Kurtzberg J, Laughlin M, Graham ML, et al. Placental blood as a source of hematopoietic stem cells for transplantation into unrelated recipients. N Engl J Med 1996; 335 (3): 157.

4. Gluckman E, Rocha V, Boyer-Chammard A, et al. Outcome of cordblood transplantation from related and unrelated donors. Eurocord Transplant Group and the European Blood and Marrow Transplantation Group. N Engl J Med 1997; 337 (6): 373.

5. Wagner JE, Barker JN, DeFor TE, et al. Transplantation of unrelated donor umbilical cord blood in 102 patients with malignant and nonmalignant diseases: influence of CD34 cell dose and HLA disparity on treatment-related mortality and survival. Blood 2002; 100 (5): 1611.

6. Passweg JR, Stern M, Koehl U, et al. Use of natural killer cells in hematopoetic stem cell transplantation. Bone Marrow Transplant 2005; 35 (7): 637.

7. Hoffmann P, Ermann J, Edinger M, et al. Donor-type CD4(+)CD25(+) regulatory $\mathrm{T}$ cells suppress lethal acute graft-versus-host disease after allogeneic bone marrow transplantation. J Exp Med 2002; 196 (3): 389.

8. Laughlin MJ, Eapen M, Rubinstein P, et al. Outcomes after transplantation of cord blood or bone marrow from unrelated donors in adults with leukemia. N Engl J Med 2004; 351 (22): 2265.

9. Laughlin MJ, Barker J, Bambach B, et al. Hematopoietic engraftment and survival in adult recipients of umbilical-cord blood from unrelated donors. N Engl J Med 2001; 344 (24): 1815.

10. Rocha V, Wagner JE, Jr., Sobocinski KA, et al. Graft-versus-host disease in children who have received a cord-blood or bone marrow transplant from an HLA-identical sibling. Eurocord and International Bone Marrow Transplant Registry Working Committee on Alternative Donor and Stem Cell Sources. N Engl J Med 2000; 342 (25): 1846.

11. Barker JN, Weisdorf DJ, DeFor TE, et al. Rapid and complete donor chimerism in adult recipients of unrelated donor umbilical cord blood transplantation after reduced-intensity conditioning. Blood 2003; 102 (5): 1915.

12. Rocha V, Labopin M, Sanz G, et al. Transplants of umbilical-cord blood or bone marrow from unrelated donors in adults with acute leukemia. N Engl J Med 2004; 351 (22): 2276.

13. Kadereit S, Kozik MM, Junge GR, et al. Cyclosporin A effects during primary and secondary activation of human umbilical cord blood $\mathrm{T}$ lymphocytes. Exp Hematol 2001; 29 (7): 903.

14. Kaminski BA, Kadereit S, Miller RE, et al. Reduced expression of NFAT-associated genes in UCB versus adult CD4 + T lymphocytes during primary stimulation. Blood 2003; 102 (13): 4608.

15. Risdon G, Gaddy J, Stehman FB, Broxmeyer HE. Proliferative and cytotoxic responses of human cord blood T lymphocytes following allogeneic stimulation. Cell Immunol 1994; 154 (1): 14.

16. Porcu P, Gaddy J, Broxmeyer HE. Alloantigen-induced unresponsiveness in cord blood $\mathrm{T}$ lymphocytes is associated with defective activation of Ras. Proc Natl Acad Sci U S A 1998; 95 (8): 4538.

17. Hesse MD, Karulin AY, Boehm BO, et al. A T cell clone's avidity is a function of its activation state. J Immunol 2001; 167 (3): 1353.
18. Falcioni F, Shah $\mathrm{H}$, Vidovic $\mathrm{D}$, et al. Influence of CD26 and integrins on the antigen sensitivity of human memory T cells. Hum Immunol 1996; 50 (2): 79.

19. Rininsland FH, Helms T, Asaad RJ, et al. Granzyme B ELISPOT assay for ex vivo measurements of T cell immunity. J Immunol Methods 2000 240 (1-2): 143

20. Helms T, Boehm BO, Asaad RJ, et al. Direct visualization of cytokineproducing recall antigen-specific $\mathrm{CD} 4$ memory $\mathrm{T}$ cells in healthy individuals and HIV patients. J Immunol 2000; 164 (7): 3723.

21. Verdonck LF, Dekker AW, de Gast GC, et al. Allogeneic bone marrow transplantation with a fixed low number of T cells in the marrow graft. Blood 1994; 83 (10): 3090.

22. Heeger PS, Greenspan NS, Kuhlenschmidt S, et al. Pretransplant frequency of donor-specific, IFN-gamma-producing lymphocytes is a manifestation of immunologic memory and correlates with the risk of posttransplant rejection episodes. J Immunol 1999; 163 (4): 2267.

23. Terakura S, Murata M, Nishida T, et al. A UGT2B17-positive donor is a risk factor for higher transplant-related mortality and lower survival after bone marrow transplantation. Br J Haematol 2005; 129 (2): 221.

24. Hentschke P, Remberger M, Mattsson J, et al. Clinical tolerance after allogeneic hematopoietic stem cell transplantation: a study of influencing factors. Transplantation 2002; 73 (6): 930.

25. Laughlin MJ, Rizzieri DA, Smith CA, et al. Hematologic engraftment and reconstitution of immune function post unrelated placental cord blood transplant in an adult with acute lymphocytic leukemia. Leuk Res 1998; $22(3): 215$.

26. Forsthuber T, Yip HC, Lehmann PV. Induction of TH1 and TH2 immunity in neonatal mice. Science 1996; 271 (5256): 1728.

27. Hussey GD, Watkins ML, Goddard EA, et al. Neonatal mycobacterial specific cytotoxic T-lymphocyte and cytokine profiles in response to distinct BCG vaccination strategies. Immunology 2002; 105 (3): 314.

28. Vekemans J, Amedei A, Ota MO, et al. Neonatal bacillus CalmetteGuerin vaccination induces adult-like IFN-gamma production by CD4+ T lymphocytes. Eur J Immunol 2001; 31 (5): 1531.

29. Garcia AM, Fadel SA, Cao S, Sarzotti M. T cell immunity in neonates. Immunol Res 2000; 22 (2-3): 177.

30. Siegrist CA. Vaccination in the neonatal period and early infancy. Int Rev Immunol 2000; 19 (2-3): 195.

31. Adkins B. Development of neonatal Th1/Th2 function. Int Rev Immunol 2000; 19 (2-3): 157.

32. Sarzotti M, Robbins DS, Hoffman PM. Induction of protective CTL responses in newborn mice by a murine retrovirus. Science 1996; 271 (5256): 1726.

33. Chalmers IM, Janossy G, Contreras M, Navarrete C. Intracellular cytokine profile of cord and adult blood lymphocytes. Blood 1998; 92 (1): 11.

34. Klein AK, Patel DD, Gooding ME, et al. T-Cell recovery in adults and children following umbilical cord blood transplantation. Biol Blood Marrow Transplant 2001; 7 (8): 454.

35. Salama AD, Najafian N, Clarkson MR, et al. Regulatory CD25+ T cells in human kidney transplant recipients. J Am Soc Nephrol 2003; 14 (6): 1643.

36. Fuller TC, Fuller A. The humoral immune response against an HLA class I allodeterminant correlates with the HLA-DR phenotype of the responder. Transplantation 1999; 68 (2): 173.

37. Baron F, Schaaf-Lafontaine N, Humblet-Baron S, et al. T-cell reconstitution after unmanipulated, CD8-depleted or CD34-selected nonmyeloablative peripheral blood stem-cell transplantation. Transplantation 2003; 76 (12): 1705.

38. Martinez C, Urbano-Ispizua A, Rozman C, et al. Immune reconstitution following allogeneic peripheral blood progenitor cell transplantation: comparison of recipients of positive CD34+ selected grafts with recipients of unmanipulated grafts. Exp Hematol 1999; 27 (3): 561. 